\title{
The Effects of Severe Zinc Deficiency on Intestinal Permeability: An Ultrastructural Study
}

\author{
J. ROBERTO MORAN AND JON C. LEWIS \\ Departments of Pediatrics and Palhologl: Bowman Gray School of Medicine of Wake Forest University, \\ Winston-Salem, North Carolina 27103
}

\begin{abstract}
Evidence suggests that intestinal transport of water and electrolytes may be altered in zinc deficiency. We examined the structural features of intestinal epithelial cells of zinc-deficient rats using electron microscopy and assessed the integrity of the junctional complexes using a heavy metal tracer, lanthanum hydroxide. The absorptive cells, as well as Paneth cells and chromaffin cells, were not found to have ultrastructural changes of a consistent nature in zinc deficiency. Moreover, the integrity of the junctional complexes was found to be preserved. These findings suggest that the abnormalities in intestinal transport previously reported are not secondary to increased tight junction permeability in zinc deficiency. (Pediatr Res 19: 968-973, 1985)
\end{abstract}

Abbreviations

\section{$Z D$, zinc deficient}

PF, pair fed

Zinc is an essential trace element for humans and animals. Its biological importance stems primarily from its key role in many vital enzyme systems. Moreover, zinc appears to have a major role in nucleic acid metabolism, protein synthesis, and in the maintenance of the structure and function of biomembranes. Deficiency of this nutrient may lead to diarrhea, weight loss, and growth retardation $(1,2)$.

Although the association of chronic diarrhea and growth retardation has been extensively studied (3-5), there have been no detailed studies on the mechanisms underlying those entities during zinc deficiency. Intestinal mucosal histology is relatively preserved (6.7): however, recent studies have demonstrated that the intestinal transport of sodium and water is impaired in zincdeficient rats (8). Further, increased losses of fecal nitrogen (9) and amino acid (10) have been reported. Hence, intestinal permeability may be altered during zinc deficiency and may contribute to the diarrhea and growth retardation.

Intercellular spaces of epithelia are thought to have important regulatory functions in the transepithelial movement of ions and water (11). Specifically, the component of the junctional complex closest to the lumen, the tight junction, plays a major role in regulating epithelial permeability by influencing paracellular flow of fluid and solute. Moreover, structural changes in tight junctions have been described in a variety of epithelia under experimental conditions in which epithelial permeability has been correspondingly altered (12). Alteration in tight junction perme-

Received November 14, 1984; accepted April 30. 1985

Correspondence and reprint requests may be addressed to J. Roberto Moran. M.D. Department of Pediatrics. Bowman Gray School of Medicine of Wake Forest University, 300 South Hawthorne Road. Winston-Salem. NC 27103.

Supported in part by National Institutes of Health Grant RR05404. ability may lead to backleaking of ions and macromolecules into the intestinal lumen and may prevent diffusion from proceeding down a concentration gradient in the paracellular space into the lamina propia. The end result of this may be deficient net absorption of ions and water and, consequently, chronic diarrhea.

The experiments described herein were undertaken to assess the integrity of junctional complexes in rats with severe zinc deficiency using an extracellular marker, lanthanum hydroxide. Knowledge of tight junction structure and permeability would provide an insight in the pathogenesis of the diarrhea of zinc deficiency.

\section{METHODS}

Animals and diets. Male, weanling Sprague-Dawley rats (Charles River Breeding Laboratories, Wilmington, MA) were randomly separated into two groups. All rats were housed individually in stainless steel cages, water bottles were equipped with silicone stoppers, and stainless steel feeders were used. The animals in the ZD group were fed ad libitum double distilled water plus a semipurified pelleted diet (Teklad Co., Madison, WI) containing only $0.5 \mathrm{ppm}$ zinc. A PF group was fed tap water plus a diet identical in composition except for zinc content of 50 $\mathrm{ppm}$. These animals were fed an amount of diet equal to that consumed by ZD.

After $5 \mathrm{wk}$ on their respective diets, the ZD animals exhibited loss of hair and diarrhea. At $6 \mathrm{wk}$, unfed (12 to $18 \mathrm{~h}$ ) rats were sacrificed with an overdose of an intraperitoneal injection of ethylurea-phenobarbital mixture (6:1) (K \& K Laboratories, Plainview, NY). After opening the abdominal cavity, $10-\mathrm{cm}$ segments of jejunum and the entire colon excluding the cecum were isolated and serial biopsies were obtained.

Trace metal analysis. The levels of zinc in plasma, tissues, and diets were measured by atomic absorption spectrophotometry (Perkin-Elmer Model 603, Perkin-Elmer Corp, Norwalk, CT) with an air-acetylene flame. Jejunum and colon were dried at $110^{\circ} \mathrm{C}$ for $20 \mathrm{~h}$ and dry weights were recorded. Dried tissues were ashed at $500^{\circ} \mathrm{C}$ for $24 \mathrm{~h}$ and residues were dissolved and appro-

Table 1. Wt of rats and jeiunum, colon, and serum zinc at death in the two study groups (means $\pm S E$ )

\begin{tabular}{lcc}
\hline & PF & ZD \\
\hline$n$ & 8 & 8 \\
Initial wt $(\mathrm{g})$ & $60 \pm 3$ & $58 \pm 3$ \\
6-wk wt $(\mathrm{g})$ & $191 \pm 8$ & $96 \pm 7^{*}$ \\
Jejunum zinc $(\mu \mathrm{g} / \mathrm{g})$ & $32.1 \pm 2.6$ & $16.9 \pm 1.6^{*}$ \\
Colon zinc $(\mu \mathrm{g} / \mathrm{g})$ & $16.9 \pm 1.6$ & $10.7 \pm 1.1 \dagger$ \\
Serum zinc $(\mu \mathrm{g} / \mathrm{dl})$ & $167 \pm 40$ & $59 \pm 10 \dagger$ \\
\hline
\end{tabular}

$*_{p}<0.01$ versus $\mathrm{PF}$.

$\dagger p<0.05$ versus $\mathrm{PF}$. 


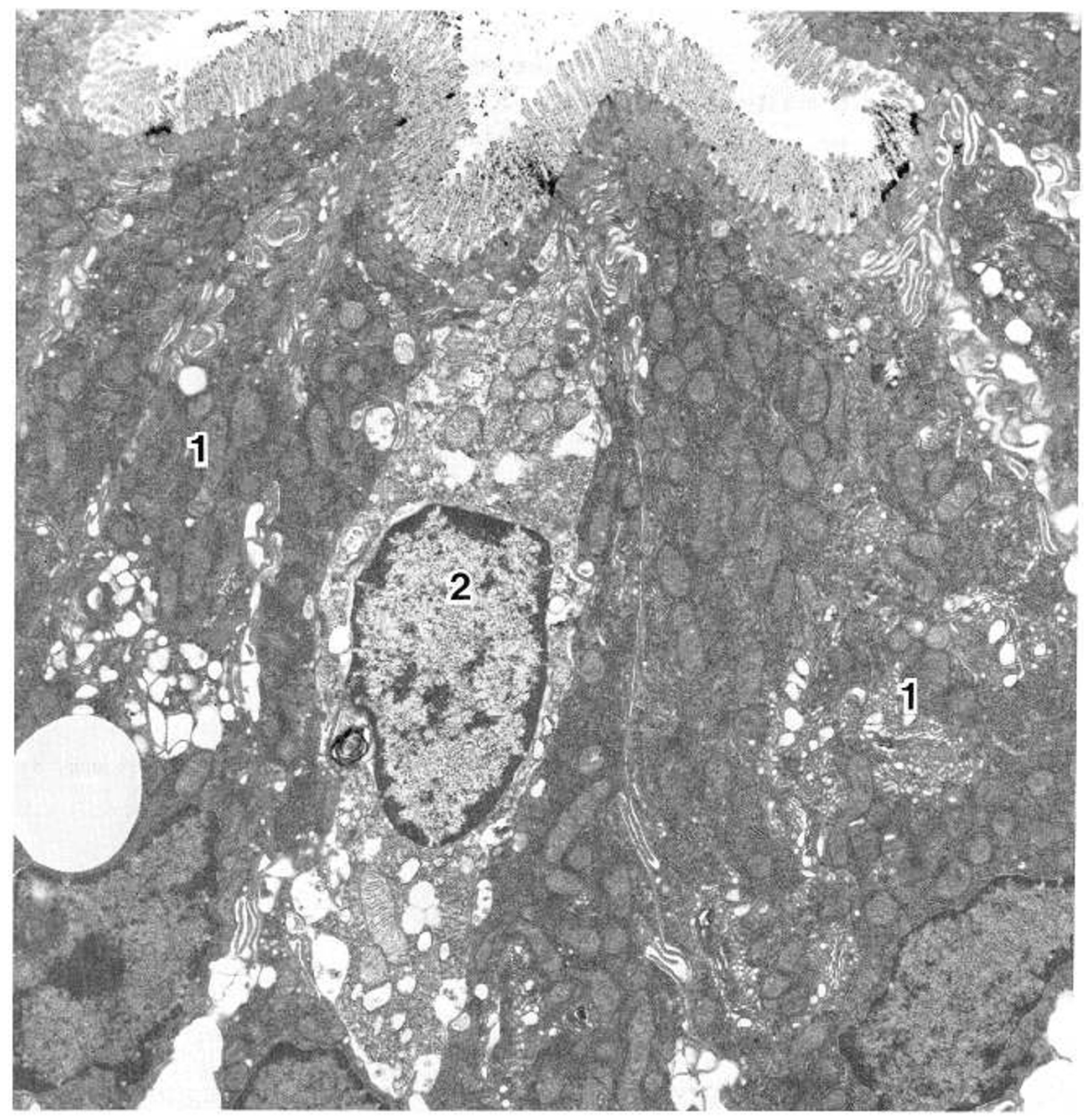

Fig. 1. Select region of the epithelium contrasting the ultrastructure of the two classes of absorptive cells in a ZD animal. The major cell type $(I)$ is characterized by highly organized, organelle-rich cytoplasm with numerous mitochondria, a basally located nucleus and a complex perinuclear Golgi. The second class of cells (2) has highly vaculated cytoplasm and a central nucleus with dense heterochromatin. $\times 11,500$.

priately diluted in $0.24 \mathrm{~N}$ ultrapure $\mathrm{HCl}$ for metal analysis Plasma samples were deproteinized by treating with three volumes of $0.77 \mathrm{~N}$ trichloroacetic acid, and the concentrations of zinc were measured in the soluble fraction (13).

Diets were wet ashed with $\mathrm{HNO}_{3} / \mathrm{HClO}_{4}$ prior to measuring the levels of zinc.

Tissue preparation for electron microscopy. Tissue was fixed at room temperature in $3 \%$ glutaraldehyde, which was buffered to pH 7.3 with $0.1 \mathrm{M}$ cacodylate. Biopsies were then rinsed in the same buffer, postfixed in $1 \%$ osmium tetroxide, dehydrated through a graded series of ethanols, and embedded in Epon 812 (14). Tissues were divided and stained with lanthanum hydroxide before embedding.
Lathanum staining was carried out by a modification (15) of the technique described by Doggenweiter and Frank (16). Lanthanum hydroxide, prepared by titration of a $3 \%$ lanthanum nitrate solution with $0.01 \mathrm{~N} \mathrm{NaOH}$, was added to the fixatives and dehydration alcohols so that the final lanthanum concentration was $1 \%$.

Sections obtained with a diamond knife in a Sorvall MT-2 ultramicrotome (Sorvall Instruments, Newtown, CT) were examined in a Philips EM 400 electron microscope. Ultrastructural studies were done on tissue segments from two animals in the control group and two of the ZD group. The histological studies for the latter group were prepared from the animals who had the lowest serum and tissue zinc concentrations. Six tissue blocks 
were processed from each of the animals (a total of 24 segments) and six to eight grids with sections were collected from each block studied. Individual grids contained 10 to 12 epoxy sections. The final microscopic analysis encompassed a total sample in excess of 300 sections. Approximately $50 \%$ of these were from the ZD group. To minimize bias during ultrastructural analysis, tissue samples were encoded by EM laboratory personnel with a dated five digit identification number. Samples were processed, sectioned, and observed as identified only by sample number. The experimental identity of the samples was unknown during ultrastructural analysis, and all observations were made and recorded using the digital identification code. Microscopic analysis of the samples was done by one of the investigators (JCL) who recorded all observations on standardized data flow-sheets. Notations were made on cellular features in both the villus tip and crypt regions where the structural integrity of Paneth cells, argentafin cells, absorptive cells, and goblet cells was recorded. With all samples, particular attention was paid to the presence or absence of lanthanum tracer in the junctional complex regions. The number of junctional complexes observed was not tabulated; however, each of the sections contained 100 to 200 clearly identifiable complexes, therefore the observational base encompassed several thousand junctions. Cross-identification of the samples as ZD or control was not done until completion of microscopic analysis.

\section{RESULTS}

Serum and intestine zinc concentrations were significantly depressed in the ZD rats compared to the PF controls (Table 1).
As previously reported, animals on the ZD diet demonstrated depressed growth rate and developed skin lesions typical of zinc deficiency.

The morphology of intestinal cells in the ZD animals is illustrated in Figures 1 and 2. General architecture in zinc deficiency was normal with an intact brush border, well-defined goblet cells, and a highly organized absorptive epithelium. The absorptive cells comprised two ultrastructural classes. the major of which was characterized by cells having an electron-dense, organellerich cytoplasm and a basally positioned nucleus. The second class, which accounted for less than $10 \%$ of the population, was characterized by cells having a vacuolated cytoplasm and a prominent, centrally positioned nucleus containing distinct heterochromatin (Fig. 1). The mitochondria, Golgi apparatus, and endoplasmic reticulum were intact in the electron-dense cells, whereas slight dilatation of mitochondria and endoplasmic reticulum was typical of the electron lucent cells. Both absorptive cell types had residual body-like lysosomes with diameters in the range 0.5 to $1.0 \mu \mathrm{m}$. Such lysosomes were not appreciably increased in the ZD animals (Fig. 1). In addition to these major cell types, both Paneth cells and chromaffin cells were identified in the crypts; and, as with the other cell types, ultrastructural changes of a consistent nature were not associated with zinc deficiency (Figure 2).

It was conceivable that altered intestinal transport, although not associated with specific structural changes in the cells, could result from subtle changes in cell association, particularly at the junctional complexes. To explore this question, tissues were fixed and processed in the presence of lanthanum, a heavy metal tracer

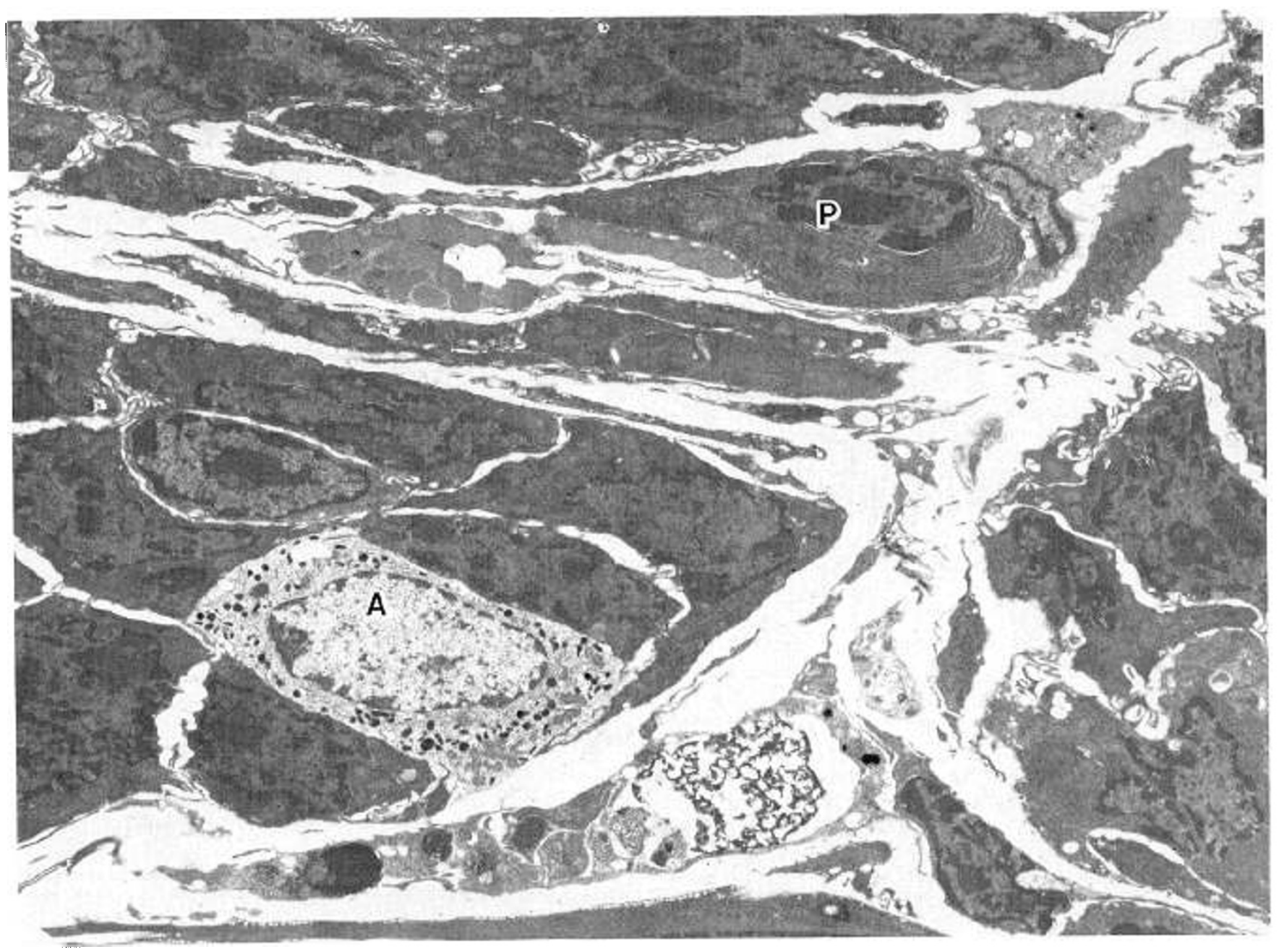

Fig. 2. Overview micrograph of the crypt region from a $Z D$ animal. Normal Paneth $(P)$ and Argentaffin cells $(A)$ were observed in all animals. $\times 4500$. 


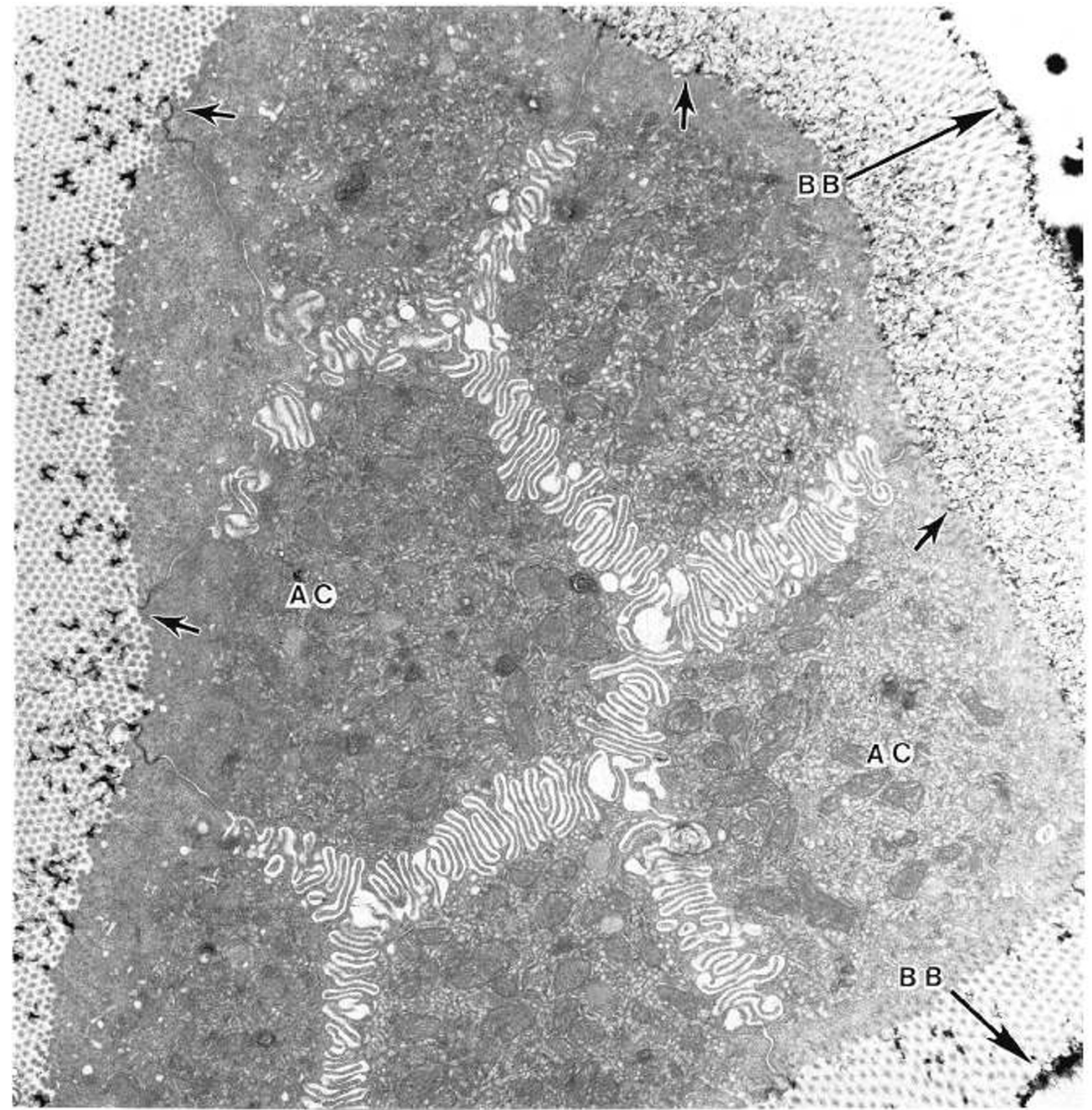

Fig. 3. Cross-section through the apical region of a villus from a lanthanum stained tissue in a ZD animal. The electron dense tracer is concentrated along the luminal aspect of the brush border $(B B)$, as well as at the plasma membrane (arrows) of the absorptive cells $(A C)$. $\times 12,500$.

which displaces plasma membrane calcium resulting in an electron-dense deposit along all exposed cell surfaces. In both the normal and ZD animals, the tracer was deposited along the luminal surface of epithelium where microvilli were enshrouded ooth at the apical and basal surfaces (Fig. 3). Typically, Ianhanum was concentrated on the luminal aspect of the plasma nembrane immediately adjacent to the junctional regions (Fig. 4). At these locations, the tracer penetrated to the zona occludens tight junction) region of the junctional complex but at no time was observed in the lateral extracellular space in any of the sections examined.

\section{DISCUSSION}

The association of chronic diarrhea and zinc deficiency has seen established $(1,2)$ and previous studies have suggested that the pathogenesis of the diarrhea may be multifactorial. Reduced intestinal disaccharidases activities (17) and abnormal lipid absorption have been reported (18). Thus, maldigestion and malabsorption of nutrients may, at least in part, account for the diarrhea and malnutrition seen in zinc deficiency. Moreover, a recent study has suggested that $Z D$ rats have decreased net transport of sodium and water when measured in vivo (8). However, the mechanisms underlying these findings could not be defined.

There is now substantial evidence that tight junctions play a major role in regulating epithelial permeability by influencing paracellular flow of fluid and solute (19). Tight junctions consist of an apical circumferential band in which the lateral membrane of adjacent cells are closely opposed. This structure is formed by a meshwork of interconnecting strands that are composed of a 


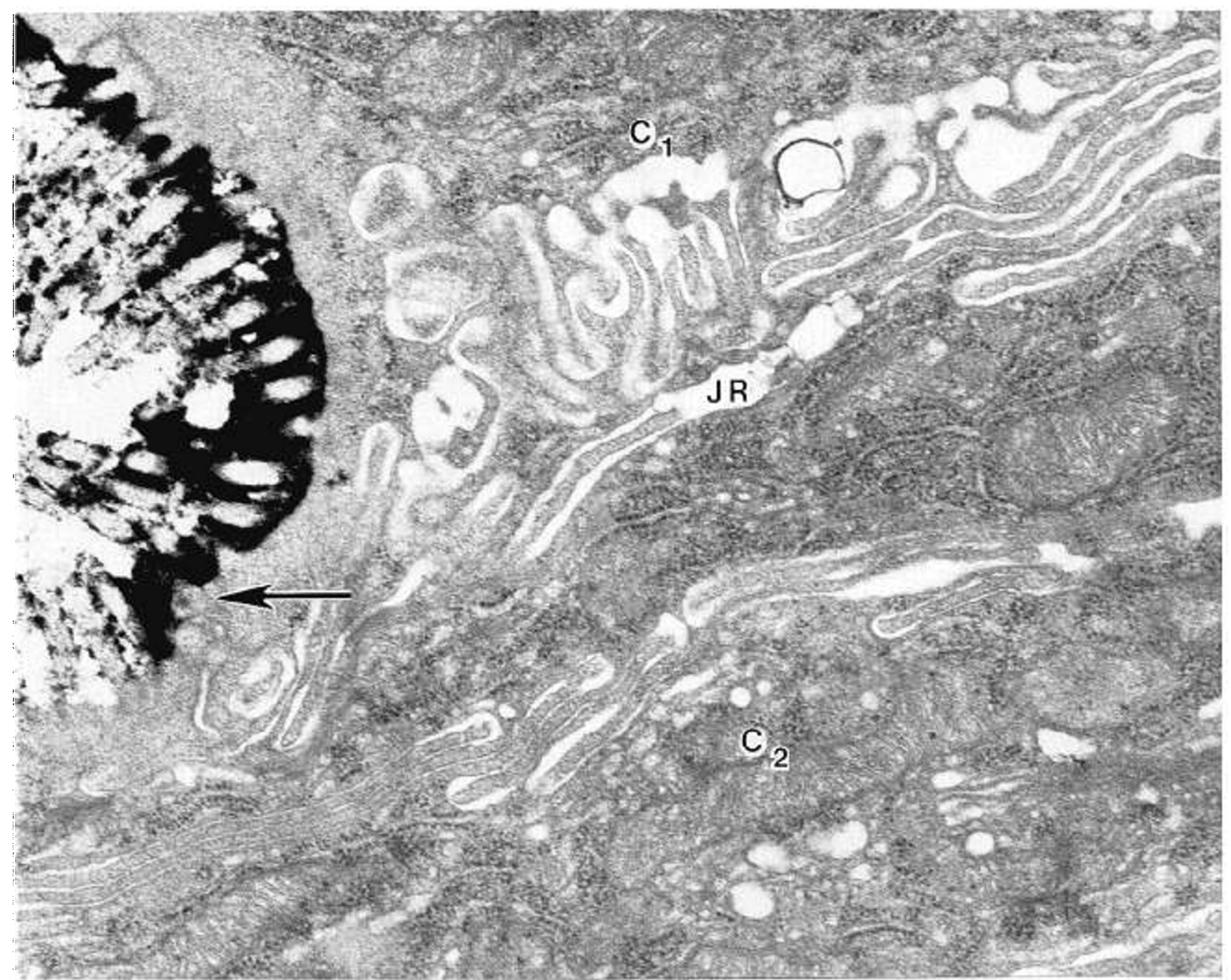

Fig. 4. High magnification of a junctional region between two absorptive cells $(\mathrm{Cl}$ and $\mathrm{C} 2)$ in a $\mathrm{ZD}$ animal. The tortuous junctional region $(J R)$ between the cells is devoid of lanthanum, yet the tracer is concentrated on the luminal side of the junctional complex (arrow). $\times 40,000$.

chain of closely spaced particles. These particles are assumed to represent integral membrane proteins (11). Since zinc plays an important role in the stability of biomembranes and tight junction structure appears to correlate closely with permeability, it seemed reasonable to hypothesize that the abnormalities in sodium and water reported to occur in zinc deficiency might be explained by alterations in the structure or function of the tight junction. We reasoned that any change in permeability might be detectable with the extracellular marker lanthanum. When used as in the present study, the lanthanum nitrate molecule dissociates resulting in the free lanthanum cation having an atomic radius of $1.15 \AA$. In this ionic form lanthanum movement is not size restricted and, therefore, serves as an excellent tracer for discontinuities between cells. In addition the ion will penetrate cells having damaged membranes and serve as an indicator of general cell pathology.

The present study shows no demonstrable structural alterations of junctional complexes when examined using a specific extracellular stain. After inducing severe zinc deficiency, no major changes were found in rat jejunum and colon epithelia. Further, junctional areas in the jejunum and colon appear to exclude the penetration of extracellular stain. Our results are consistent with those of Machen et al. (20) who reported no significant penetration of lanthanum between adjacent epithelial cells of normal rabbit ileum when tissue was fixed and then exposed to lanthanum.
Despite the apparent absence of specific morphological changes and preserved paracellular permeability, significant alterations in the transport of nutrients, ions, and water seem to occur during zinc deficiency. It is conceivable, therefore, that these abnormalities may be due to deficient transepithelial transport processes where "carrier proteins" are involved. Further studies are currently underway to examine this hypothesis.

\section{REFERENCES}

1. Sandstead HH 1982 Nutritional role of zinc and effects of deficiency. In: Winick M (ed) Adolescent Nutrition. John Wiley and Sons, New York, pp $97-124$

2. Underwood EJ 1977 Zinc. In: Trace Elements in Human and Animal Nutrition. Academic Press, New York, pp 196-242

3. Black RE, Brown KH, Becker S, Yunus M 1982 Longitudinal studies of infectious diseases and physical growth of children in rural Bangladesh. I. Patterns of morbidity. Am J Epidemiol 115:305-314

4. Black RE, Brown KH, Becker S. Abdul Alim Arm, HUQI 1982 Longitudinal studies of infection and physical growth of children in rural Bangladesh II. Incidence of diarrhea and association with known pathogens. Am J Epidemiol 1 15:315-324

5. Martorell R. Yarbrough C, Lechtig A, Habieht JP, Klein RE 1975 Diarrheal diseases and growth retardation in preschool Guatemalan children. Am J Phys Anthropol 43:341-356

6. Elmes MC, Jones JG 1980 Ultrastructural changes in the small intestine of zinc deficient rats. J Pathol 130:37-43

7. Wilson ID, McClain CJ, Erlandsen SL 1980 Ileal Paneth cells and IgA system in rats with severe zinc deficiency: an immunohistochemical and morphological study. Histochem $\mathbf{J}$ 12:457-471 
8. Ghishan FK 1984 In vivo water. electrolytes and glucose transport in the zinc deficient rat. J Pediatr Gastroenterol vutr 3:608-612

9. Verma U. Kawatra BL. Bajay S 1981 Effect of feeding zinc deficient Bengal grass (Cicer arietenum) diet to rats on the in vitro absorption of 1.-histidine monohydrochloride. Fxperientia 37:1295-1296

10. Moran JR. Lyerly AD 1985 The effects of sevre zinc deficiency on intestinal amino acid losses in the rat. Life Sci 36:2515-2521

11. Trier JS. Madara JL 1981 Functional morphology of the mucosa of the small intestinal. In: Johnson LC (ed) Physiology of the Gastrointestinal Tract. Raven Press. New York. pp 952-961

12. Civan MM. DiBona DR 1978 Pathways for movement of ions and water across toad urinary bladder. III. Physiologic significance of the paracellular pathway. J Membr Biol 38:359-386

13. Butrimovitz. JP. Purdy CVC 1977 The determination of zinc in blood plasma by atomic absorption spectrometry. Anal Chem Acta 94:63-66

14. Luft JH 1961 Improvements in cpoxy resin embedding methods. J Biophys
Biochem Cytol 9:409-414

15. Resel JP. Karnovsky MJ 1967 Hexagonal array of sub units in intercellular junctions of the mouse heart and liver. J Cell Biol 33:C7-C12

16. Doggersweiter CF, Frank S 1965 Staining properties of lanthanum on cell membranes. Proc Natl Sci USA 53:425-430

17. Gebhard PL. Karouani R, Prigge WF, McClain CJ 1983 The effect of severe zinc deficiency on activity of intestinal disaccharidases and 3-Hydroxy-3.methylglutaryl Coenzyme A reductase in the rat. J Nutr 113:855-859

18. Koo SI, Turk DE 1977 Effect of zinc deficiency on intestinal transport of triglyceride in the rat. J Nutr 107:909-919

19. Schultz SG, Zalusky R 1964 Ion transport in isolated rabbit ileum. II. The interaction between active sodium and active sugar transport. J Gen Physiol 47:1043-1054

20. Machen TE. Ertij D. Wooding FBP 1972 Permeable junctional complexes: the movement of lanthanum across rabbit gallbladder and intestine. J Cell Biol $54: 302-312$ 